\title{
DEVELOPMENT OF VARIABLE THICKNESS LONGITUDINAL PROFILED ROLLED PLATE AT GERDAU OURO BRANCO
}

\author{
Afrânio Márcio Costa \\ Antônio Augusto Gorni ' \\ Emanuelle Garcia Reis '\# \\ Jose Herbert Dolabela da Silveira '
}

\begin{abstract}
Gerdau Ouro Branco's plate mill started operation in 2016 with high-level technology and production capacity of I.2 million tons per year. The plant has the capacity to produce different thicknesses in a single plate, therefore is able to supply special requirements of sectors such as building structures, bridges, shipbuilding and mechanical applications. This paper presents the first results obtained in this innovative product in South America market. Some slabs of EN I0025-2 S355JR+AR steel were rolled and were evaluated for dimensional tolerances, mechanical properties uniformity, grain size, surface and internal qualities. In addition, a correlation was observed between slab and plate thickness reduction and internal plate quality. The results show that this technology can be used with adequate performance for steel grades in the current market.
\end{abstract}

Keywords: Plate mill; New product; Longitudinal plate.

\section{INTRODUCTION}

Bridge and ship designers demand plates with different thickness depending on the load applied to the structures on most projects. Normally, the lower parts of structures use larger thickness, while upper parts can be made with smaller plate thickness. This is due to the usual load distribution in these structures [I]. Thus, it is often necessary to use bolted joints in bridge projects, resulting in increased weight and cost. This also lowers productivity during local erection. Figure I shows one example.

Increasing steel resistance to reduce the structure weight, promote cost reduction, and lowering environmental impact and increasing productivity in assembly has been the objective of much research [2-5].

Combined with the development of high strength steels, new technologies have been developed by steelmakers, with emphasis on the longitudinal rolling of different thicknesses in a single plate [6-8]. The greatest motivating factor for this development was the reduction of weld length, with consequent increase in safety and in structure resistance, as applied to bridge building or shipbuilding. Ihara et al.[6] showed that this new solution for civil construction has some benefits such as better appearance and the elimination of bolted joints and filler plates.

Various thickness profile can be produced with this technology. Examples of the different shape profiles that can be produced at Gerdau Ouro Branco are shown in Figure 2.

\section{METHODOLOGY}

First, two plates of steel grade EN I0025-2 S355JR+AR were rolled with different longitudinal profiles and characterized. The chemical composition of this steel grade is shown in Table I.

The thickness profile was as shown in Figure 3.

The slabs were cast according to the parameters given in Table 2.

The slabs internal quality was evaluated by macro etching. The sampling position is shown in Figure 4.

Plate samples were taken according to the scheme shown in figures 5 and 6 . The exact sampling position on the width of the plate was decided based on the results observed on the slab macroetched samples and on the plate ultrasonic test. All macroetch samples were taken in direction transverse to casting and rolling.

The mechanical properties, microstructure, grain size, segregation and micro hardness were evaluated in each plate. All samples were removed from the same width plate position to guarantee the same internal quality effect. All samples were taken according to Figure 5 and 6 . Tensile mechanical properties were measured transverse to rolling direction while impact test was taken on longitudinal samples.

\section{RESULTS AND DISCUSSION}

The macro etching images of the slab (transverse samples) in the positions according to Figure 4 are show in Figure 7.

The macro etching results were evaluated according to Mannesmann rating system. The results are presented in Table 3.

'Gerdau, Ouro Branco, MG, Brasil.

${ }^{\#}$ Corresponding author E-mail: emanuelle.reis@gerdau.com.br 
Table I. Steel grade chemical composition.

\begin{tabular}{ccccccccc}
\hline Grade & C[\%] & Mn[\%] & Si[\%] & Al[\%] & Nb+V+Ti[\%] & P[\%] & S[\%] & N[ppm] \\
\hline S355 & $0,13-0,19$ & $1,30-1,60$ & $0,15-0,25$ & $0,02-0,05$ & $0,08-0,12$ & $<0,025$ & $<0,01$ & $<80$ \\
\hline
\end{tabular}

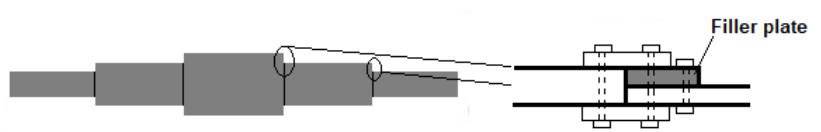

Figure I. Conventional plate used in traditional bridge flange [I].

Longitudinally

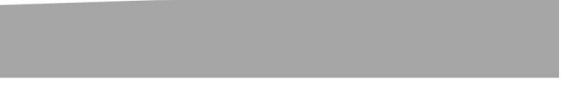

Differential thickness

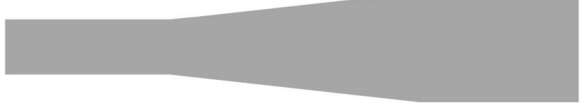

Multi thickness

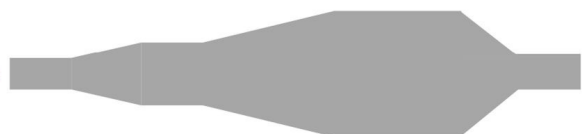

Figure 2. Different longitudinal plate profiles.

(a)

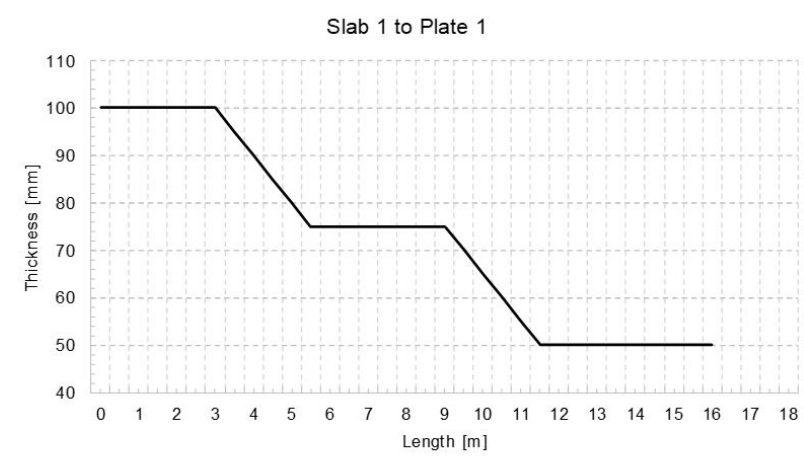

(b)

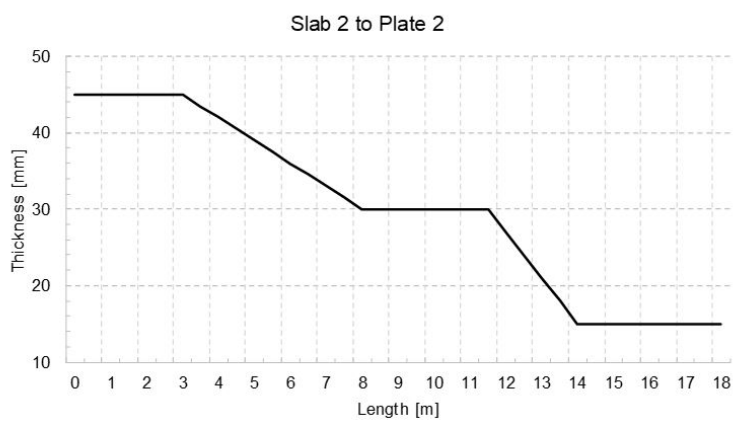

Figure 3. Plate's thickness profile (a) slab I to plate I and (b) slab 2 to plate 2.

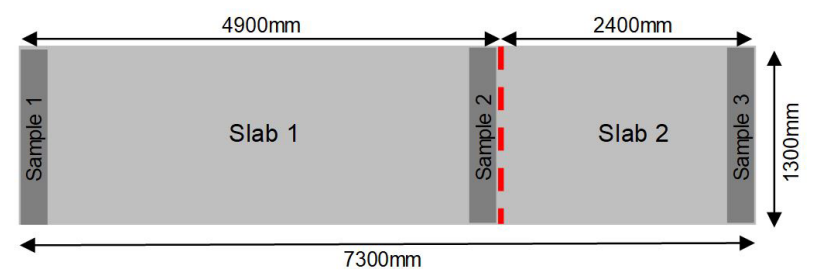

Figure 4. Slab samples for macro etching.
Table 2. Slabs casting conditions.

\begin{tabular}{ll}
\hline Thickness [mm] & 250 \\
Width [mm] & 1.300 \\
Casting speed [m/min] & 1,25 \\
Dynamic Soft Reduction rate $[\mathrm{mm} / \mathrm{m}]$ & 1,41 \\
Soft Reduction $[\mathrm{mm}]$ & 6,50 \\
Secondary Cooling rate $[1 / \mathrm{kg}]$ & 0,45 \\
\hline
\end{tabular}

Table 3. Macro etching results for each slab sample.

\begin{tabular}{cccc}
\hline Steel Grade & Slab sample & $\begin{array}{c}\text { Segregation } \\
\text { index }\end{array}$ & Crack index \\
\hline S355 & $\mathrm{I}$ & $\mathrm{I}$ & 0 \\
& 2 & $\mathrm{I}$ & 0 \\
& 3 & $\mathrm{I}$ & 0 \\
\hline
\end{tabular}

(a) Plate 1

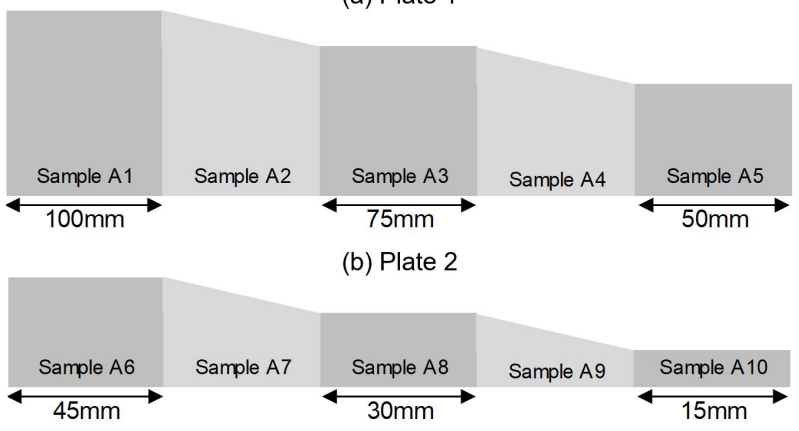

Figure 5. Plate sample design.

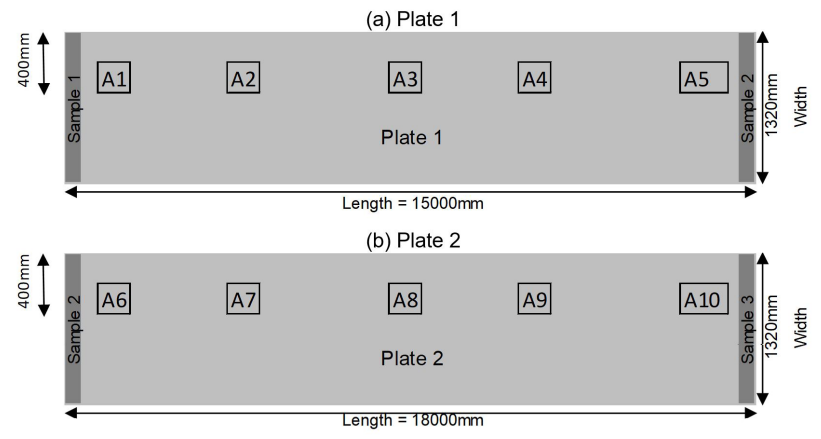

Figure 6. Sample position on plates.

The internal slab quality was very good for these applications. This is further evidenced by the good ultrasonic test results of the plates according EN I0I60-S2EI standard.

Visually, the flatness of the rolled plate was good as shown in Figure 8.

The thermographic picture (Figure 9) shows that the temperature profile of this plate, at the end of rolling was uniform, as desired. This indicates that the mechanical properties should also be uniform as expected. 
The thickness profile was evaluated and compared with that predicted by rolling model.

The different values of thickness at the beginning and end of plates are discarded during trimming cutting.

The mechanical properties are show in figures 10 until I 5.
All mechanical properties results have met the products specifications along the transversal direction.

The microstructures (Figure 16) show that for the different thickness the ferritic grain refinement occurs as the reduction rate increase [9].

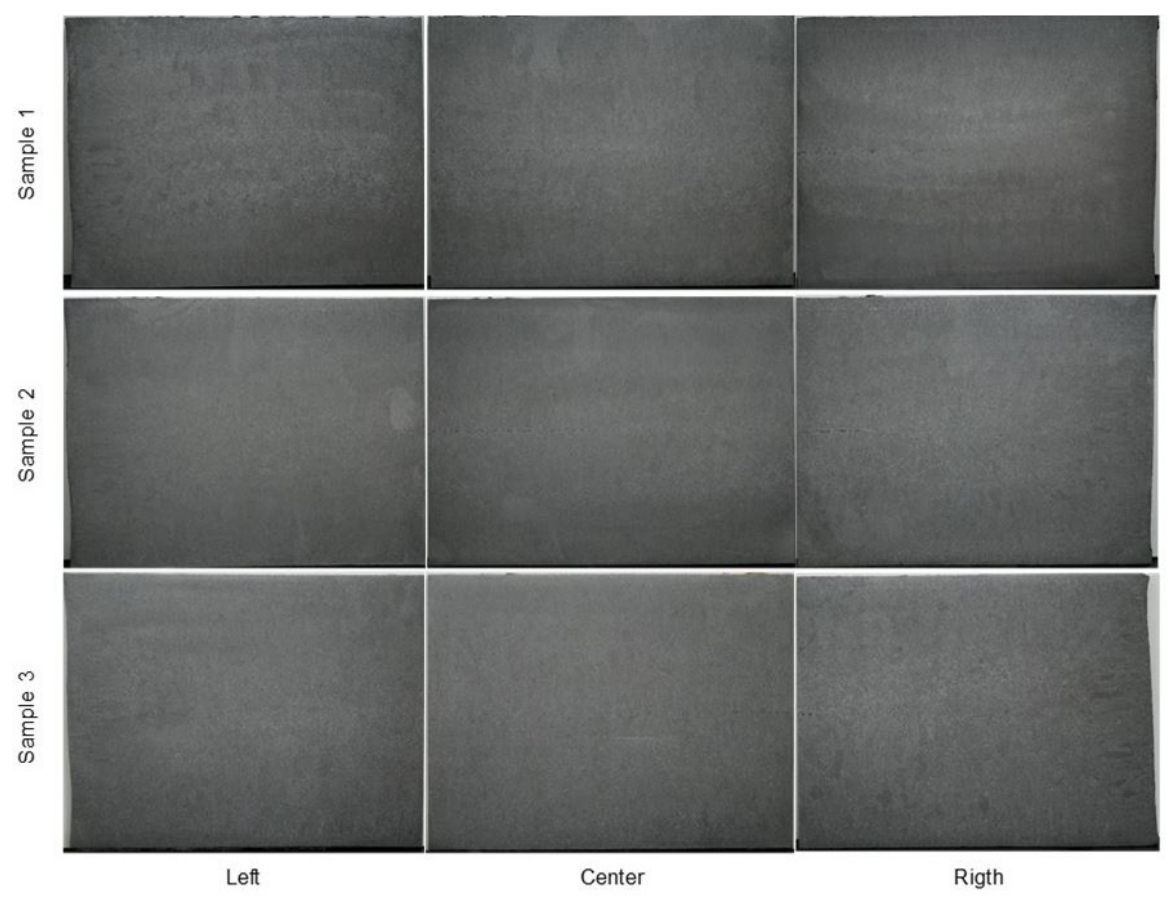

Figure 7. Macro etching results for slabs. Sample with $250 \times 300 \mathrm{~mm}$ on transversal section.

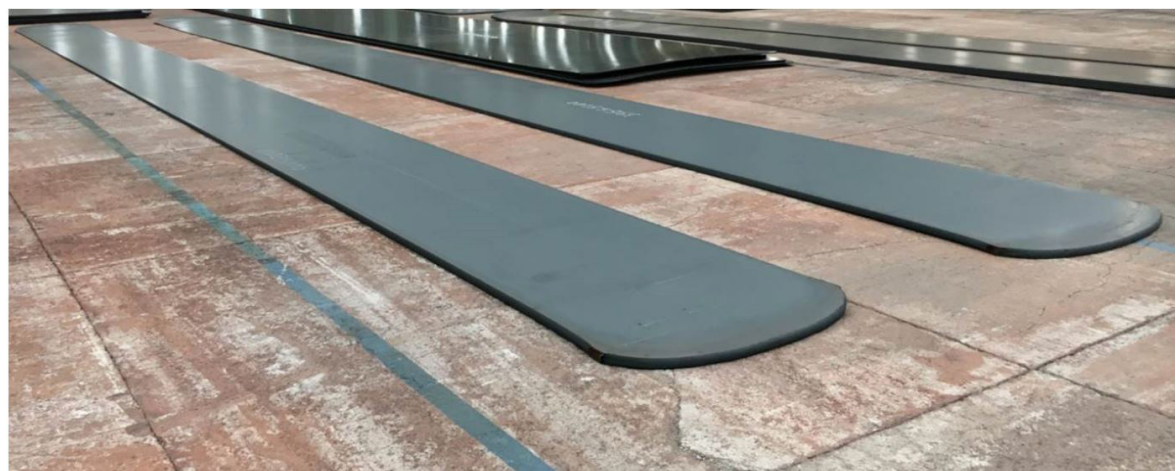

Figure 8. Plate photography on plate yard.

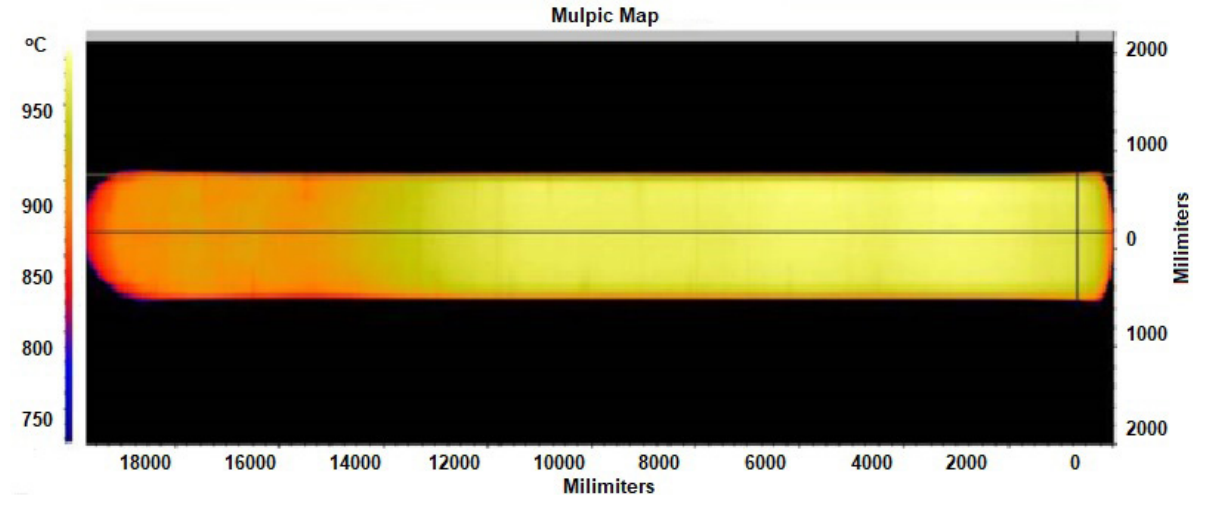

Figure 9. Plate I thermal profile. 
(a) S355 plate 1

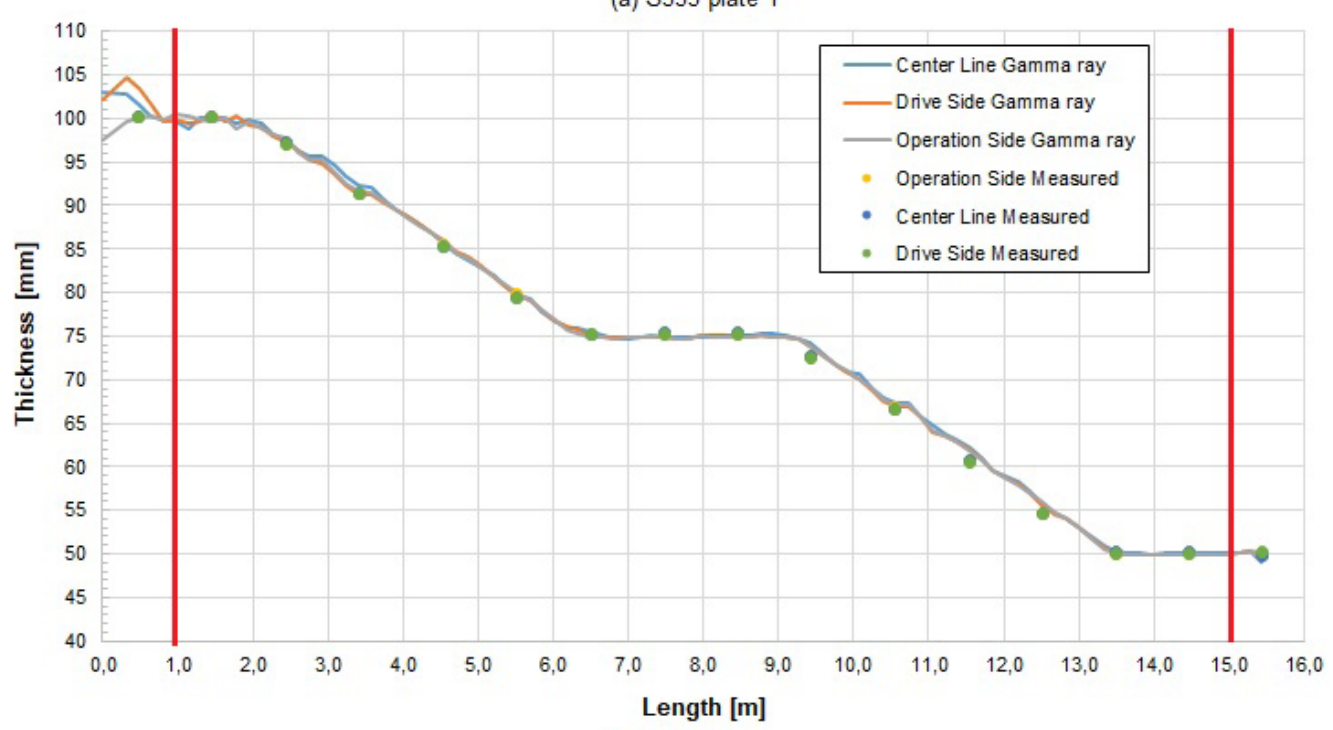

(b) $\mathrm{S} 355$ plate 2

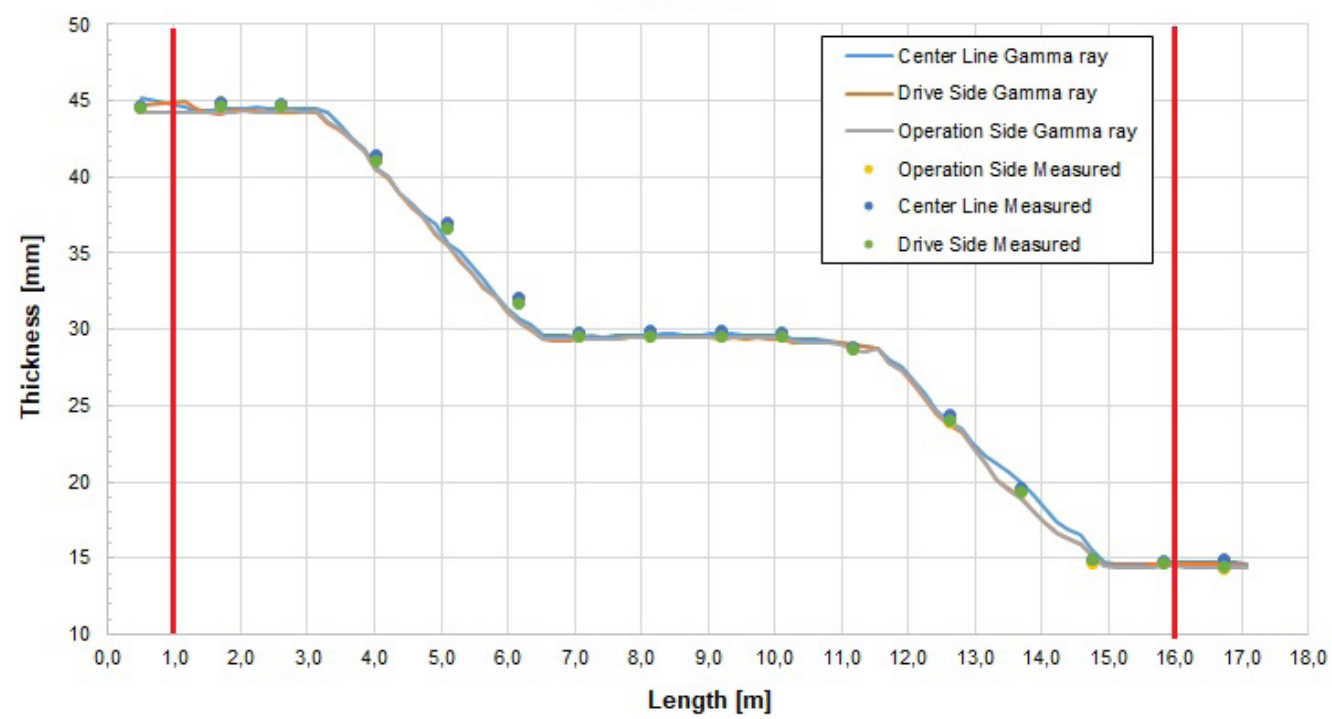

Figure 10. Real thickness profile.

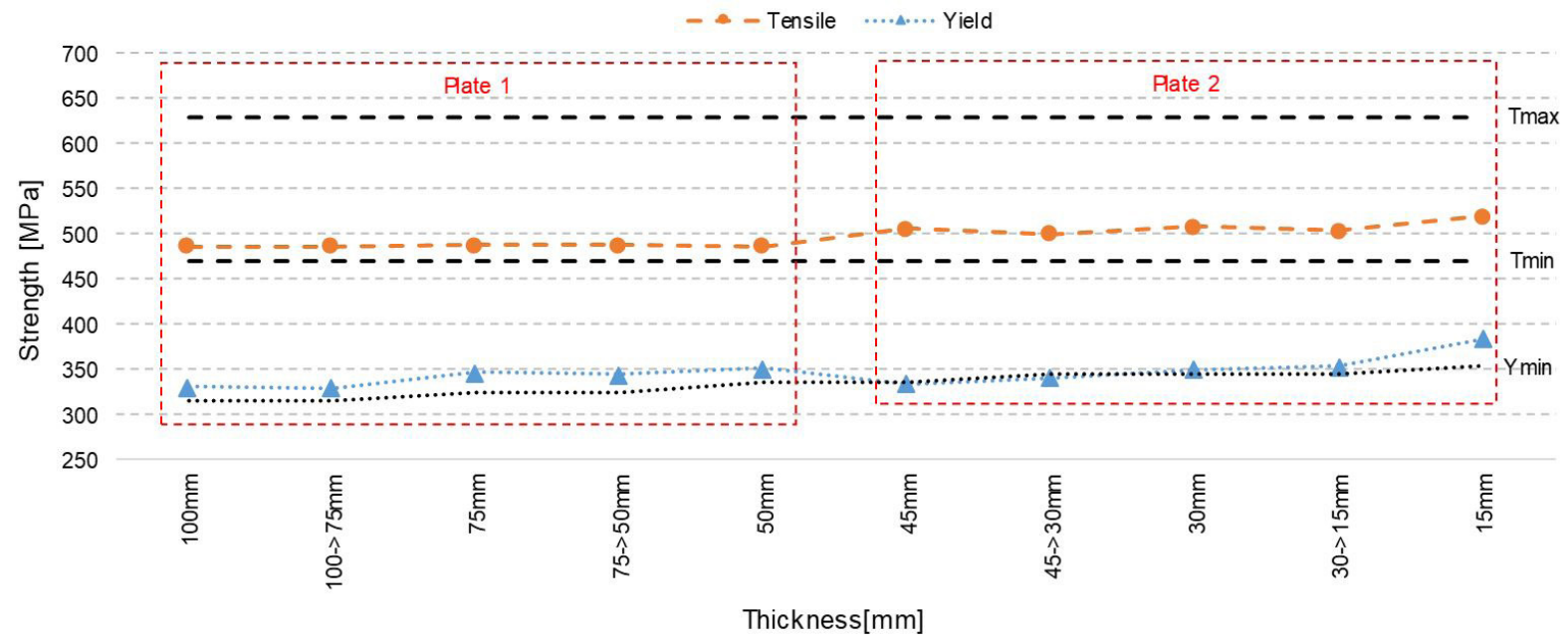

Figure I I. Strength results. $Y=y i e l d, T=$ tensile, transverse specimens, measured according to EN I0002-I:200 I in as-rolled plates. 
$1 / 4$ thickness, Longitudinal direction, $-400 \mathrm{C}$

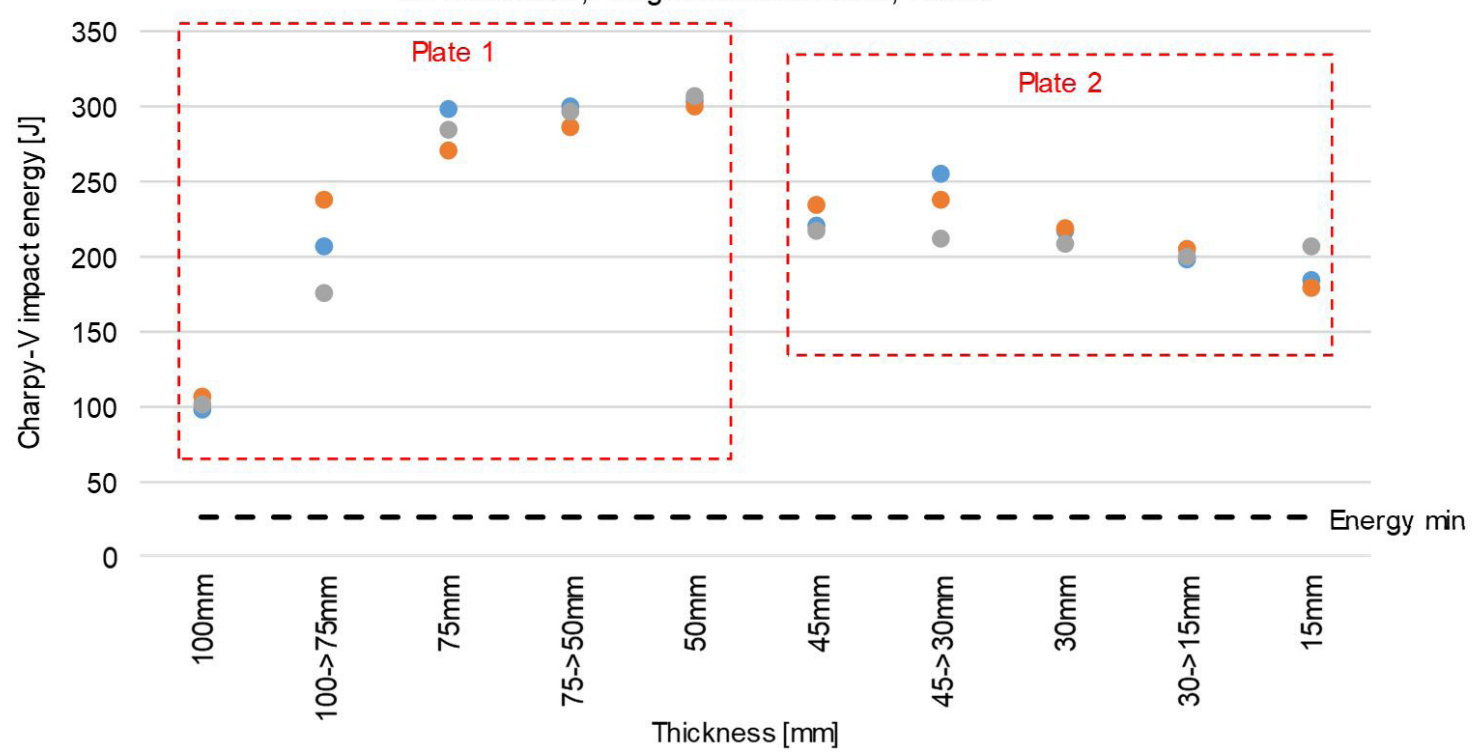

Figure 12. S355 charpy results according to EM 10045-I.

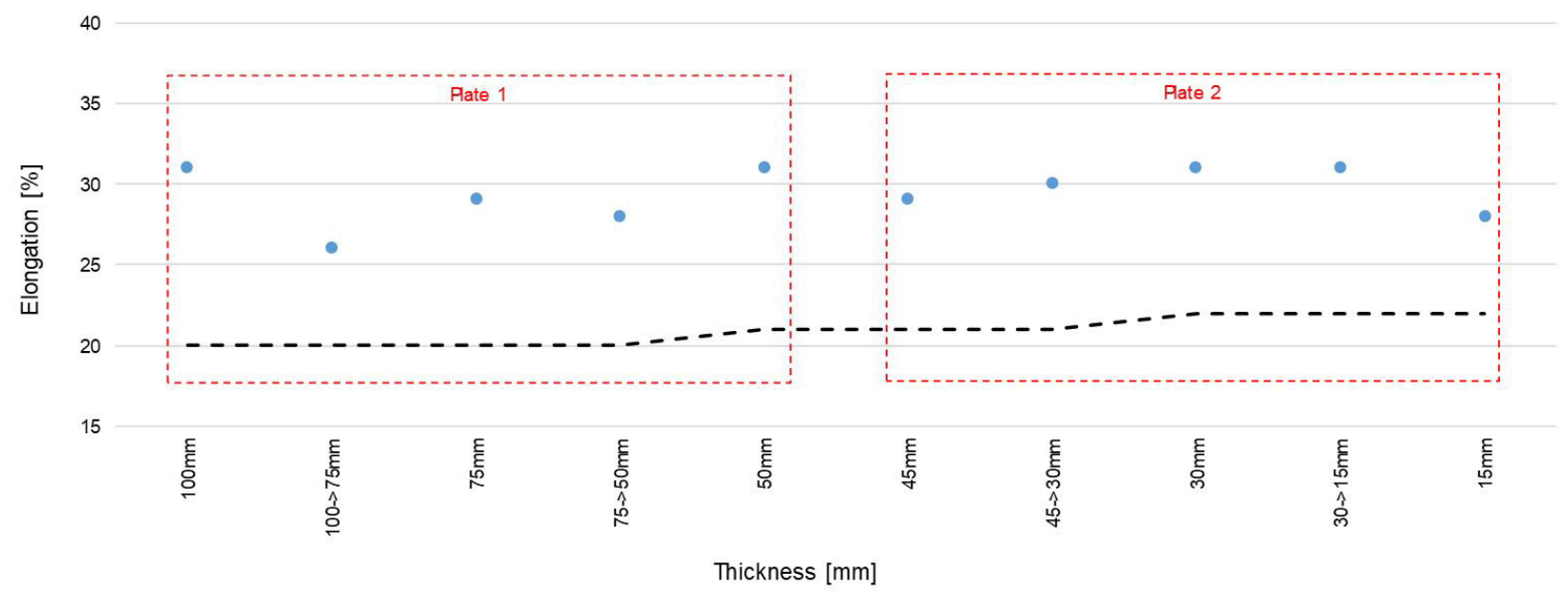

Figure I3. S355 elongation results according EM 10025-2.

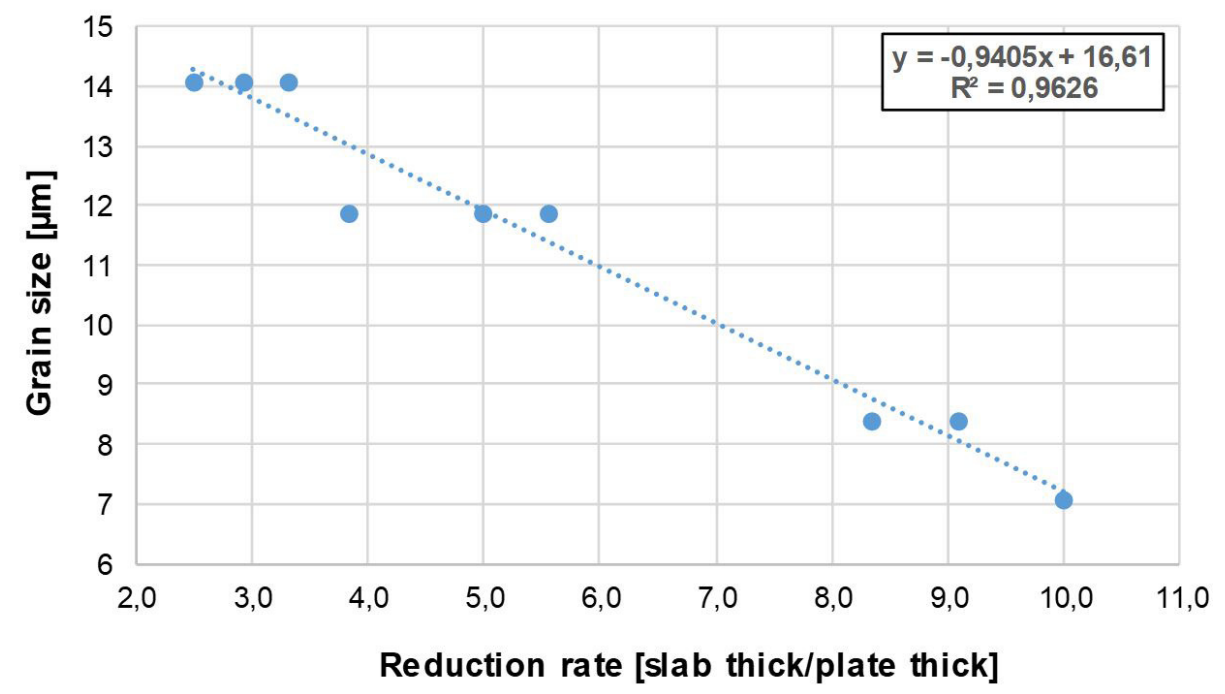

Figure 14. S355 Ferritic grain size measured according to ASTM EI I 2 correlated to hot rolling reduction rate of plates. 


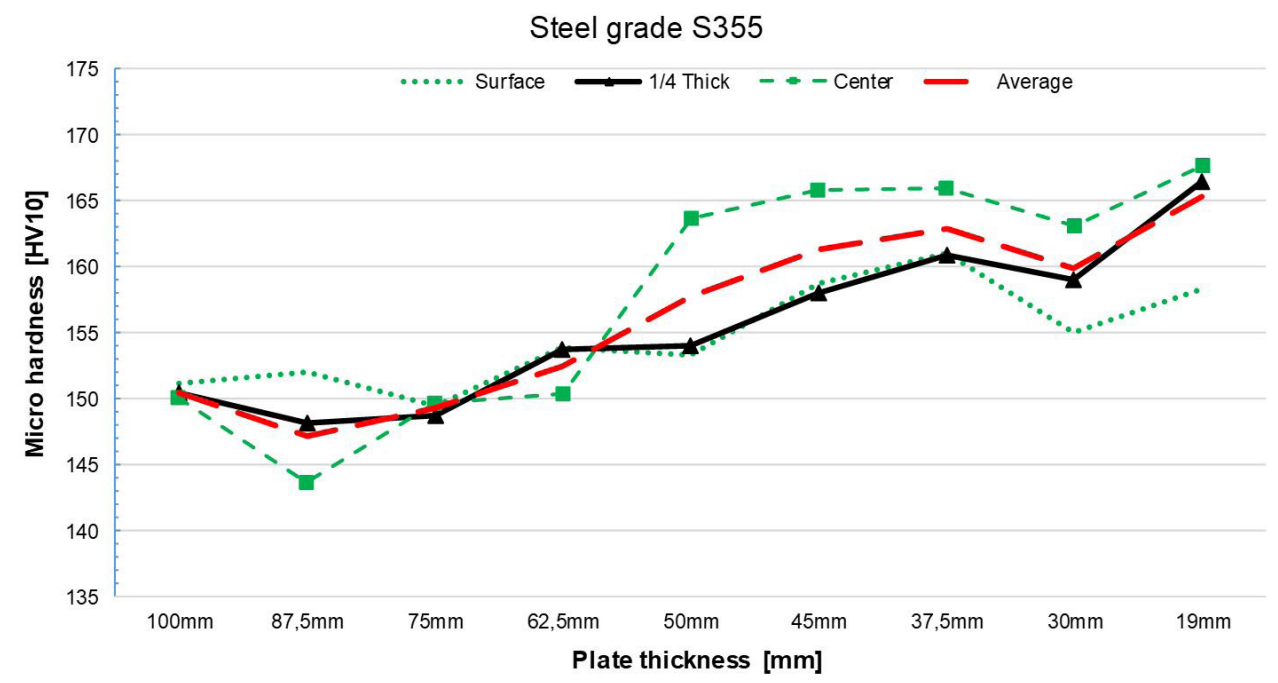

Figure I5. Micro hardness results.
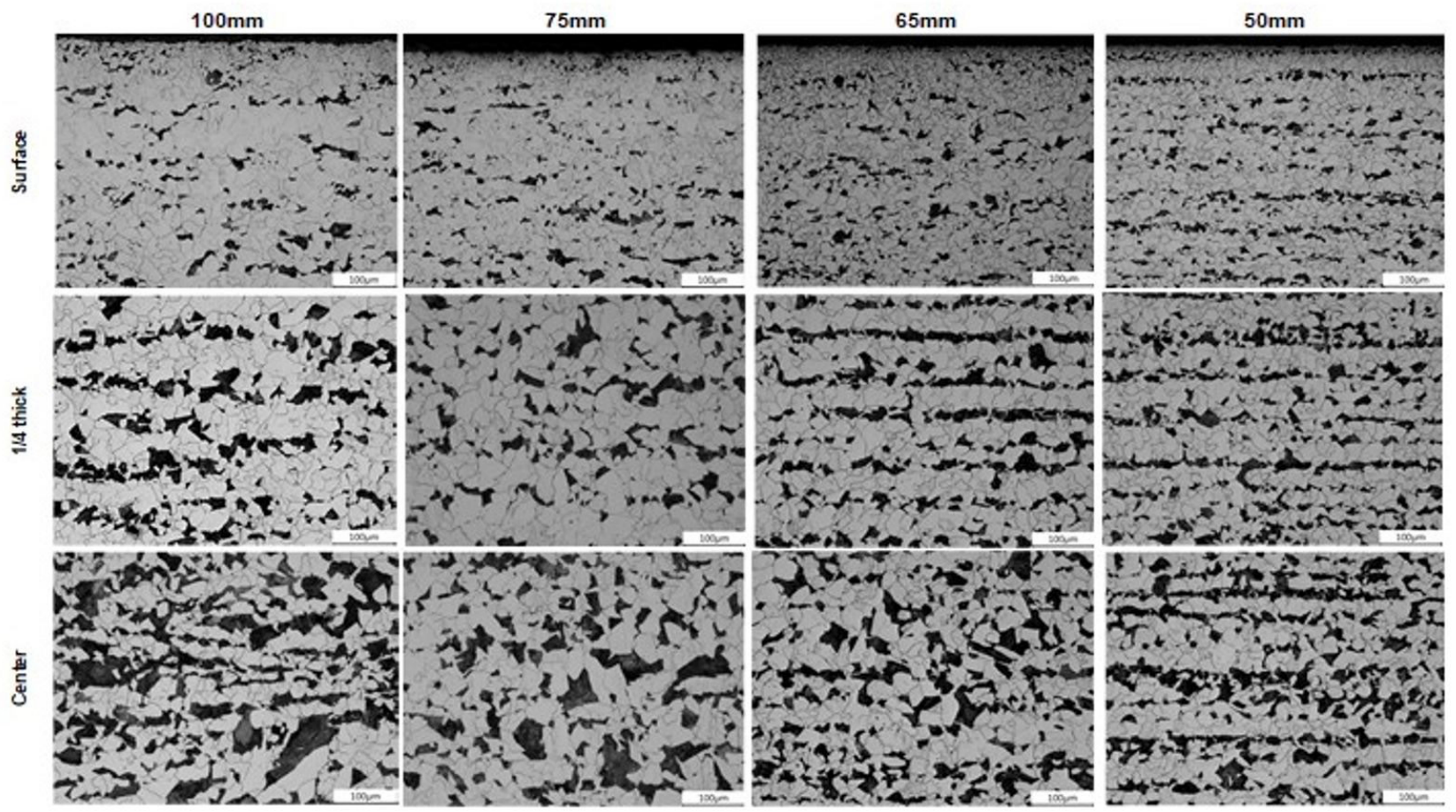

Figure 16. Microstructure for different thickness.

\section{CONCLUSION}

This new product has adopted an innovative solution to serve the civil construction and shipbuilding markets with significant gains in productivity, cost reduction, lower environmental impact and greater sustainability $[10,11,12]$.
The mechanical properties results show uniformity along the plate length and guarantee capacity to provide plate with different thicknesses in the longitudinal rolling direction. The development at GERDAU Ouro Branco made available this type of products in South America.

\section{REFERENCES}

I Dillinger Hutte. Internal Report: Advanced Structural Engineering Steels. Germany: Dillinger; 2018.

2 Willms R. High Strength steel for steel constructions. In: Proceedings of the I I th Nordic Steel Construction Conference; 2009 September 2-4; Malmö, Sweden. Stockholm: SBI; 2009. p. 597-604. 
3 Stroetman, R. High Strength Steel for Improvement of Sustainability. In: Proceedings of the 6th European Conference on Steel and Composite Structures, Proceedings Volume C. 3I; 201 I August 2 - September; Budapest, Hungary. page 1959-1964. 201 I.

4 Ilic $A$, Ivanovic L, Josifovic $D$, Lazic V. Advantages of high strength steels applications in mechanical constructions. In Proceedings of the 7th International Symposium KOD; 2012 May 24-26; Balatonfured, Hungary. Bratislava: Faculty of Mechanical Engineering; 2012.

5 Nishioka, K, Ichikawa, K. Progress in Thermomechanical Control of Steel Plates and their Commercialization. Sci Technol Adv Mater. 20 I2; I3(2): I-20.

6 Ihara K, Yuge Y, Matsunaga N. Development of manufacturing technologies of high performance longitudinal profiled steel plates. JFE Technical Report. 2015;20:34-39.

7 Tanigawa O, Kohriyama T, Amano K. Development of high-performance steel plates for reliable and economical steel structures. Kawasaki Steel. 20I4;44:62-70.

8 Lehnert T. Special heavy plates and steel solutions for bridge building. Materials Science and Engineering. 2017:236:1-7.

9 Shiping L, Qun L, Zhiyong W, Linhao G, Xuanming Z. The Research and development of longitudinal profiled (LP) plate. MATEC Web of Conferences. 2018;175:I-3.

10 Kawabata F, Matsui K, Obinata T, Komori T, Takemura M. Steel Plates for Bridge Use and Their Application Technologies. JFE Technical Report. 2004;2:78-82.

I I Nomiyama Y, Yasui H. Latest Plate Production Technology of Nippon Steel \& Sumitomo Metal Corporation. Nippon Steel Technical Report. 2015; I 10:8-16.

12 Maier, P., Kuhlmann U, Pfaffinger M, Mensinger M, Schneider S, et al. Sustainability Assessment of bridges - Recent German.

Received: 16 Jan. 2020

Accepted: 23 Mar. 2020 